\title{
IMPORTANCE OF THE TRIPLE TEST AND FREQUENCY OF BREAST CANCER IN WOMEN SUBMITTED TO THE EXEMPTION OF BREAST NODE
}

Waldemar N. Amaral1', Maryanne O. Silva², Valdivina E. Falone³, Ana C. A, Costa², Murilo H. C. Silva1', Thaynara M. Pacheco', Bruna O. Andrade', Lucas V. Peixoto'

${ }^{1}$ Universidade Federal de Goiás - Goiânia (GO), Brazil.

${ }^{2}$ Hospital e Maternidade Dona Iris - Goiânia (GO), Brazil.

${ }^{3}$ Faculdade da Polícia Militar - Goiânia (GO), Brazil.

Objective: To establish the importance of preoperative diagnostic exams in breast nodules. Methodology: A retrospective, descriptive, cross-sectional study was carried out through the selection of medical records of women submitted to breast node excision at HMDI (Hospital and Maternity Dona Iris) between January 2016 and December 2017. Results: Maternity in the mastology outpatient clinic, being selected only those patients who underwent breast node excision, totaling 121 cases. Of these patients, 48 (39.7\%) were between 15 and 25 years old. The triple test was performed in $60 \%$ of patients, and the results were respectively: 41 (56.2\%) benign, 21 (28.8\%) suspects and 11 (15.1\%) malignant. The anatomopathological ones, 108 (89.3\%) were diagnosed as benign breast diseases and 13 (10.7\%) were diagnosed as breast cancer. $72.7 \%$ had a fibroadenoma diagnosis with the highest prevalence in the group aged 15-35 years. No nodules were diagnosed as malignant in the 15-25 age group, all of them fibroadenoma. There was 1 case of breast cancer in the age group of 26 to 35 years; there were 4 cases in the 36 to 45 years, and 8 cases in the over 46 years. An important finding is that only 10 patients (13\%) of the age group up to 35 years had nodules smaller than $2 \mathrm{~cm}$ and ultrasound was not suspected, and surgery was not indicated. Conclusion: The importance of preoperative diagnostic tests in breast nodules is to predict benignity or malignancy. The triple test showed diagnostic excellence. The prevalence of breast cancer was $10.7 \%$. The accuracy of the triple test was $94.9 \%$, and the sensitivity of $100 \%$. The most common histological finding was fibroadenoma. 